\title{
Novel nanomolar imidazo[4,5-b]pyridines as selective nitric oxide synthase (iNOS) inhibitors: SAR and structural insights
}

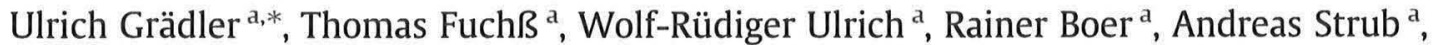 \\ Christian Hesslinger ${ }^{a}$, Céline Anézo ${ }^{a}$, Kay Diederichs ${ }^{b}$, Andrea Zaliani ${ }^{a}$ \\ ${ }^{a}$ Nycomed GmbH, Byk-Gulden-Str. 2, D-78467 Konstanz, Germany \\ ${ }^{\mathrm{b}}$ Fachbereich Biologie, Universität Konstanz, Box M647, D-78457 Konstanz, Germany
}

\begin{abstract}
A B S T R A C T
Inducible arginine oxidation and subsequent NO production by correspondent synthase (iNOS) are important cellular answers to proinflammatory signals. Prolonged NO production has been proved in higher organisms to cause stroke or septic shock. Several classes of potent NOS inhibitors have been reported, most of them targeting the arginine binding site of the oxygenase domain. Here we disclose the SAR and the rational design of potent and selective iNOS inhibitors which may be useful as antiinflammatory drugs.
\end{abstract}

Keywords:

Nitric oxide synthase (NOS; EC 1.14.13.39) generates the important neurotransmitter and cytotoxic agent NO via oxidation of L-arginine. ${ }^{1}$ Three major isoforms have been identified in mammals: neuronal NOS (nNOS), inducible NOS (iNOS) and endothelial NOS (eNOS). ${ }^{2,3}$ They share $50-60 \%$ sequence identity and have identical overall architecture. The known NOS enzymes are active as a homodimer, and each monomer is comprised of a catalytic $\mathrm{N}$-terminal oxygenase domain, a C-terminal reductase domain and a calmodulin binding linker. The oxygenase domain (NOS $\mathrm{Nx}_{\text {) }}$ binds the substrates L-arginine and $\mathrm{O}_{2}$ and contains the two cofactors heme and 5,6,7,8-(6R)-tetrahydrobiopterine $\left(\mathrm{BH}_{4}\right)$ and a structural zinc atom. Electrons are supplied to the $\mathrm{O}_{2}$ bound heme from the NADPH-binding reductase domain involving the cofactors FAD and FMN. ${ }^{4}$

The constitutively expressed isoforms nNOS and eNOS are regulated by $\mathrm{Ca}^{2+} /$ calmodulin and produce low levels of NO (100-500 $\mathrm{nmol} / \mathrm{mg} \mathrm{min})$ predominantly for both nerve function and blood pressure regulation, respectively. In contrast, the inducible isoform is controlled at the transcription level and expressed in response to proinflammatory signals. ${ }^{5}$ Because iNOS is often expressed at high levels over longer time periods, the overproduction of NO (1500 nmol/mg min) can lead to undiserable pathologies

\footnotetext{
* Corresponding author. Tel.: +49(0)178 4575455.

E-mail addresses: ugraedler@hotmail.com, ulrich.graedler@merck.de (U. Grädler).
}

such as stroke and septic shock. Therefore, selective inhibition of the inducible isoform can serve as a suitable strategy to target both acute and chronic inflammation. ${ }^{6}$

Several classes of potent NOS inhibitors have been reported, most of them targeting the arginine binding site of the oxygenase domain (Table 1). ${ }^{7}$ One major class of inhibitors are L-arginine analogues bearing a guanidine, amidino or isothiourea group that mimic the recognition of the guanidinium group of the substrate as confirmed by X-ray crystallography. ${ }^{8}$

Among these, the weakly selective iNOS inhibitor $\mathrm{N}$-iminoethylL-lysine (1a, L-NIL) as its tetrażole-amide acid prodrug (L-NIL-TA, SC-51) (1b, Fig. 1) has been demonstrated to reduce exhaled breath nitric oxide in patients with mild asthma. ${ }^{9,10}$ The cyclic amidine derivative ONO-1714 2 belongs to the most potent iNOS-inhibitors $\left(K_{\mathrm{i}}=2 \mathrm{nM}\right)^{9}$

Table 1

Published NOS-affinity data (given as $\mathrm{pIC}_{50}$ )

\begin{tabular}{lllll}
\hline Entry & iNOS (human) & eNOS (human) & nNOS (human) & ref \\
\hline $1 \mathrm{a}$ & 5.33 & $<4$ & 4.21 & 9 \\
$1 \mathrm{~b}$ & $<4$ & $<4$ & $<4$ & 9 \\
2 & $\mathrm{p} K_{\mathrm{i}}=8.73$ & $\mathrm{p} K_{\mathrm{i}}=7.73$ & ND & 11 \\
3 & 5.85 & 3.33 & 3.84 & 15 \\
4 & 7.43 & $<4$ & 6.13 & 16 \\
5 & 6.96 & 7.35 & ND & 17 \\
6 & 7.15 & $<4$ & 5.18 & 18 \\
\hline
\end{tabular}


<smiles>CC(=N)NCCCCC(N)C(=O)Br</smiles>

1a: $\mathrm{R}^{1}=\mathrm{O}$

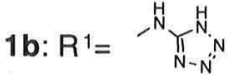<smiles>CC(=N)NCCSCCC(N)C(=O)O</smiles>

3<smiles>Cc1cc(C)nc(N)c1</smiles>

5<smiles>CC1CC(=N)NC2C(Cl)C12</smiles>

2<smiles>N#Cc1ccc(C(=O)N2CCC3(CC2)N=C(N)c2c(F)ccc(F)c2N3)cn1</smiles><smiles>COc1ccnc(NC2CCN(C(=O)c3ccc(C#N)nc3)CC2)c1</smiles>

6
Figure 1. Published iNOS inhibitors.

However, ONO-1714 shows only 10 -fold selectivity over eNOS and no selectivity over nNOS. ${ }^{11}$ Since the arginine binding-site is highly conserved among the NOS isoenzymes, structure-based design of selective inhibitors remains a challenging problem. ${ }^{12-14}$ However, several substrate mimetics, like GW-274150 3, achieve isoform selectivity through additional interactions outside of the catalytic site. ${ }^{15,16}$ Both L-arginine analogues L-NIL-TA $\mathbf{1 b}$ and GW-274150 3, respectively, have been tested in clinical phase Il for the oral treatment of migraine, rheumatoid arthritis (RA), osteoarthritis (OA), chronic obstructive pulmonary disease (COPD), asthma and allergic rhinitis. However, no further development has been reported for both compounds. A series of spirocyclic amidines such as 4 (AR-C102222) were reported as highly potent and selective iNOS-inhibitors with good oral activity. ${ }^{17}$ Several groups have identified 2-aminopyridines such as $\mathbf{5}$ as potent NOS inhibitors revealing their potential to mimic the basic amidine or guanidine group in L-arginine analogues. ${ }^{18}$ In another study, N-substituted 4-methoxy-2-aminopyridines such as 6 (AR-C133057XX) demonstrated both high potency and selectivity as iNOS inhibitors. ${ }^{19}$ Lately, several papers showed renewed interest on selective iNOS inhibitors. ${ }^{20-22}$

In a screening campaign conducted on our corporate compound library, 2-(4-methoxypyridin-2-ylmethylsulfanyl)-3H-imidazo[4, 5 -b] pyridine (7) has been identified as potent iNOS inhibitor $\left(\mathrm{pIC}_{50}=6.94\right.$, Table 2 ). NOS activity was measured by quantification of $\left[{ }^{3} \mathrm{H}\right]$ L-arginine conversion to $\left[{ }^{3} \mathrm{H}\right]$ L-citrulline. ${ }^{23}$ The selectivity profile of 7 (nNOS: $\mathrm{plC}_{50}=5.47$; eNOS: $\mathrm{pIC}_{50}=4.27$ ) provided an ideal starting point for further hit-to-lead optimization. Radioligand binding experiments demonstrated, that 13, a carbo analogue of 7 (Table 3 ), acts as a competitive inhibitor with respect to L-arginine. ${ }^{23}$ This observation suggests that 7, and the entire SAR family, interact with the L-arginine-binding site within NOS $_{\mathrm{Ox}}$ as exemplified by different classes of NOS inhibitors. ${ }^{12-16}$

Binding affinity for iNOS was also observed for the simple 7 derivative 4-methoxy-2-methylsulfanylmethyl-pyridine (10; $\mathrm{pIC}_{50}=6.81$ ). As shown in Table 2, the introduction of a second methoxy group in the 3 - or 5-position of the pyridine ring resulted in a complete loss of iNOS-affinity $\left(\mathbf{1 1}, \mathbf{1 2}\right.$; iNOS: $\left.\mathrm{pIC}_{50}<4\right)$. Interestingly, modifications of the imidazo[4,5-b]pyridine ring system also significantly affect the iNOS affinity as demonstrated by the imidazo[4,5-c]pyridine derivative 8 (iNOS: $\mathrm{plC}_{50}=4.31$ ) and the imidazobenzene analogue 9 (iNOS: $\mathrm{pIC}_{50}=4.97$ ). This initial structure-activity relationship (SAR) prompted us to use 4-methoxypyridine in combination with the imidazo[4,5-b]pyridine as templates for further optimization.
Table 2

Inhibitory activities of compounds from the first screening campaign against human NOS

\begin{tabular}{lllll}
\hline Entry & & & \\
\hline iNOS & eNOS & (nNOS \\
\hline
\end{tabular}

In the first optimization loop, a methylene group replaced the sulfur atom of 7 , because of its susceptibility for oxidation in phase I metabolism. Synthesis of 2-[2-(4-Methoxy-pyridin-2-yl)-ethyl]3H-imidazo[4,5-b]pyridine (17, BYK191023) and its selected derivatives 17-26 are shown in Scheme 1. Malonester synthesis using 4methoxy-pyridine-2-carbaldehyde 13, which was synthesized in a three-step procedure starting from commercially available 2methoxy-4-nitro-pyridine 1-oxide, yields exclusively (E)-3-(4Methoxy-pyridin-2-yl)-acrylic acid methyl ester $14 .^{24,25}$ Subsequent standard hydrogenation on palladium/charcoal and hydrolysis of the methyl ester furnished the key intermediate 3-(4methoxy-pyridin-2-yl)-propionic acid 15. iNOS inhibitors 17-26 are readily obtained by the final condensation of the corresponding 2,3-diaminopyridines and $\mathbf{1 4}$ in fresh polyphoshoric acid at elevated temperatures to afford the common $3 \mathrm{H}$-imidazo[4,5-b]pyridine moiety in a straightforward manner.

The resulting analogue BYK191023 17 (Table 3) showed both an improved iNOS-affinity ( $\mathrm{plC}_{50}=7.09$ ) and selectivity profile ( $\mathrm{nNOS}$ : $\mathrm{pIC}_{50}=4.86$; eNOS: $\left.\mathrm{plC}_{50}=3.95\right)$, respectively. ${ }^{24} \mathrm{~A}$ slightly reduced potency was observed for the 6-bromine- $\left(18\right.$; iNOS: $\left.\mathrm{plC}_{50}=6.73\right)$ and the 7-methyl-derivative (20; iNOS: $\left.\mathrm{pIC}_{50}=6.84\right)$ of 17 . The drop in binding affinity was even more pronounced by the introduction of a 5-methoxy group (19; iNOS: $\left.\mathrm{pIC}_{50}=6.42\right)$ and by 5,7-dimethyl substitution (21; iNOS: $\left.\mathrm{pIC}_{50}=5.64\right)$. Taken together, these results indicate limited space in the 5-position for further introduction of substituents. Therefore, we focused our efforts to improve potency on the 6-and 7-position of $\mathbf{1 7}$.

We next determined the binding position of $\mathbf{1 7}$ within the L-arginine binding site by X-ray crystallography using murine iNOS $_{\text {Ox. }} \cdot{ }^{8,26}$

The 4-methoxypyridine ring is inserted into the guanidinium binding site bearing $\pi$-stacking interactions to the heme (Fig. 2). 
Table 3

Inhibitory activities of selected compounds against human NOS

Entry

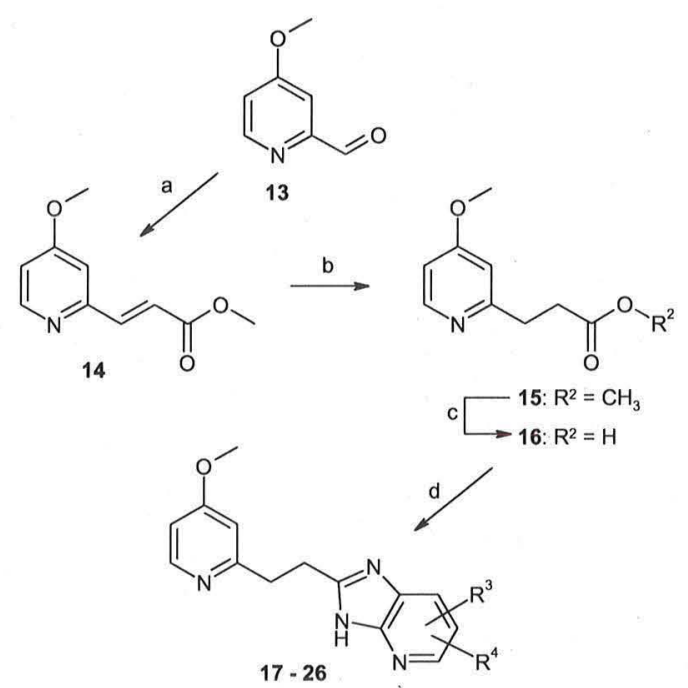

$\mathrm{R}^{3}, \mathrm{R}^{4}=\mathrm{H}, \mathrm{Br}, \mathrm{CH}_{3}, \mathrm{OCH}_{3}, \mathrm{O}\left(\mathrm{CH}_{2}\right)_{2} \mathrm{OCH}_{3}, \mathrm{O}\left(\mathrm{CH}_{2}\right)_{2} \mathrm{Ph}$, phenyl

Scheme 1. Reagents and conditions: (a) monoethyl malonate potassium salt ( 1.8 equiv), pyridine hydrochloride ( 2.0 equiv), piperidine ( 0.12 equiv), pyridine, $120^{\circ} \mathrm{C}, 2 \mathrm{~h}, 68 \%$; (b) $\mathrm{H}_{2}, \mathrm{Pd} / \mathrm{C}(10 \%), \mathrm{MeOH}, 96 \%$; (c) $\mathrm{NaOH}$ (1.0 M, 1.2 equiv), THF, r.t., 85\%; (d) 2,3-diaminopyridine derivative, polyphosphoric acid (PPA), 110$160{ }^{\circ} \mathrm{C}, 1-24 \mathrm{~h}, \leqslant 50 \%$.

An additional hydrogen bond to Glu371 is formed between the OE1-atom and an adjacent water molecule (wat1), which is also involved in an $\mathrm{H}$-bond $(3.1 \AA)$ to the N3-atom of the imidazo

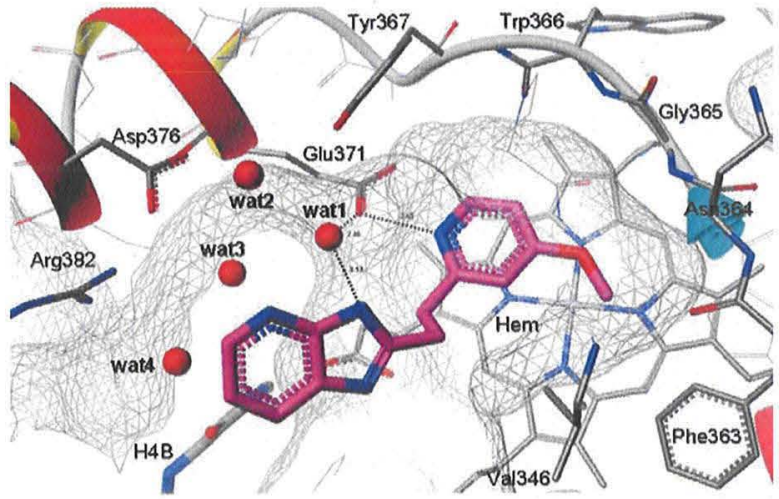

Figure 2. Crystal structure of murine iNOS in complex with 17 (PDB Code 3NW2).

[4,5-b]pyridine ring of $\mathbf{1 7}$. This water molecule is part of a fourmembered water-cluster (wat1-4) forming a polar contact area at the bottom side of the imidazo[4,5-b]pyridine ring. In agreement with the SAR, the 4-methoxy substituent of $\mathbf{1 7}$ is accomodated in a small hydrophobic pocket formed by Val346 (murine iNOS numbering) and Phe363. The different active site volumes of the three isoforms $(e N O S>$ iNOS $>n N O S$ ) in this region have been discussed as an important factor for inhibitor selectivity. ${ }^{27.28}$ In the observed binding position of $\mathbf{1 7}$, a second methoxy group in either the 3- or 5-position of the pyridine ring would result in steric clashes with the backbone of Trp372 and the side chain of Val352 respectively. This might explain the decrease in iNOS-affinity of the dimethoxy substituted pyridine derivatives $\mathbf{1 1}$ and $\mathbf{1 2}\left(\mathrm{pIC}_{50}<4\right)$ compared to 10 ( IIC $\left._{50}=6.81\right)$ with only one methoxy group in the 4-position.

The distance between the nitrogen atom of the 4-methoxypyridine and both carboxylic O-atoms of Glu371 (OE1-atom: 2.7 Å and OE2-atom: $3.3 \AA$ ) suggests a hydrogen bond and therefore a protonation of this pyridine $\mathrm{N}$-atom. Potentiometric titration experiments performed with $7\left(\mathrm{p} K_{\mathrm{a} 2}=5.31\right)$ and $17\left(\mathrm{p} K_{\mathrm{a} 2}=6.25\right)$ suggested, that the inhibitors are likely to be neutral in solution at the applied assay conditions. However, $\mathrm{p} K_{\mathrm{a}}$ values of ligands can be shifted in protein binding sites due to the electrostatic influence of the protein's titratable groups in the direct environment. ${ }^{29}$ For the complex of methotrexate (MTX) with dihydrofolate reductase (DHFR), a $\mathrm{p} K_{\mathrm{a}}$-shift from 5.7 (apo) to 7.9 (complexed) was predicted in agreement with previous experimental results. ${ }^{30}$ In a study from Astra-Zeneca researchers, in fact, the X-ray structures of iNOS in complex with 4-methyl-2-aminopyridine and the 2amino-4-methoxypyridine-derivative 6 (AR-C133057XX) revealed a bidendate charge-interaction of the (protonated) 2-aminopyridine-group to Glu371. ${ }^{19}$ Furthermore, the presence of a basic guanidine, amidino or isothiourea group has been proposed as a key recognition element in NOS inhibitors targeting the guanidine binding region. ${ }^{31}$ We therefore predict, that the $\mathrm{p} K_{\mathrm{a}}$ assigned to the 4-methoxypyridine $\mathrm{N}$-atom of $\mathbf{1 7}$ is shifted from 6.25 in solution towards higher values in the binding pocket of iNOS stabilizing appropriate protonation for salt-bridge interaction to Glu371.

The bottom part of the heterocyclic binding pocket is completed by the side chain of $\operatorname{Arg} 382$, which is hydrogen bonded to wat4 through its $\mathrm{NH} 1$-atom. Interestingly, the $\mathrm{C} 5$-atom of the imidazo[4,5-b]pyridine is in close contact $(3.3 \AA)$ to the NH2-atom of $\operatorname{Arg} 382$ and readily explains the decrease in binding affinity of the 5-methoxy- $\left(19\right.$; iNOS: pIC $\left._{50}=6.42\right)$ and of the 5,7-dimethylderivative (21; iNOS: $\mathrm{pIC}_{50}=5.64$ ) of 17 . The upper part of the imidazo[4,5-b]pyridine binding pocket is less well defined, since the side chains of the proximal residues Ser256 and $G \ln 257$ are disordered in the electron density map. Therefore, the exact role of the Ser256 and Gln257 side chains in the recognition of the imidazo[4,5-b]pyridine ring remains unclear. 


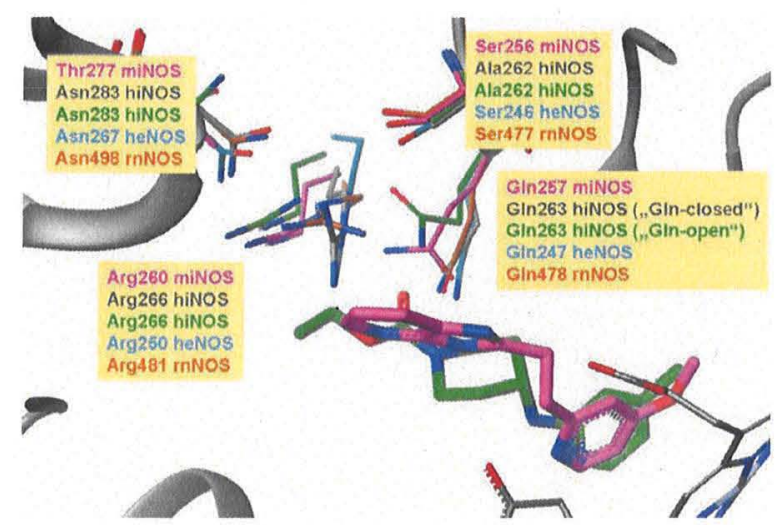

Figure 3. Superimposition of crystal structures of murine iNOS (magenta), human iNOS (grey, PDB-Code: 1NSI and green, PDB-Code: 3EZG), human eNOS (cyan, PDBCode: 3 NOS) and rat nNOS (orange, PDB-Code: $1 \mathrm{ZVL}$ ) demonstrate conformational differences of the amino acids in the vicinity of 17 . The imidazo[4,5-b]pyridine ring of $\mathbf{1 7}$ points towards the GIn specificity pocket in human iNOS involving an induced fit of Gln263 from 'closed' towards an 'open' position.

Both murine and human iNOS oxygenase domains show a high level of sequence identity (89\%) and the amino acids involved in substrate and $\mathbf{1 7}$ binding are strictly conserved. In agreement with these structural similarities, the experimental $K_{\mathrm{i}}$ of $\mathbf{1 7}$ towards the murine $\left(\mathrm{p} K_{\mathrm{i}}=6.78\right)$ and human iNOS $\left(\mathrm{p} K_{\mathrm{i}}=7.07\right)$ appears to be in the same range. ${ }^{23}$ When comparing the ligand binding sites of murine iNOS Ox $_{17}$ and human iNOS $\mathrm{Ox}$ L-arginine, significant conformational differences of Arg260 (hiNOS: Arg266) and Gln257 (hiNOS: Gln263) adjacent to the imidazo[4,5-b]pyridine ring can be observed (Fig. 3).

This region has been described as 'Gln specificity pocket' promoting isoform selectivity by sequence specific plasticity of the binding site. ${ }^{32}$ In this study, bulky derivatives of $\mathbf{6}$ induced conformational changes in human iNOS involving the rotation of Gln263 from a 'Gln-closed' position (t-arginine bound) towards a 'Glnopen' position (inhibitor bound). Although the corresponding Gln257 is not defined in the murine iNOS ox 17 structure, the side chain conformation of Arg260 corresponds to Arg266 in the 'Glnopen' structure of human iNOS (Fig. 3). The induced fit of Arg266 is supplemented by the rotation of Asn283 (nNOS: Asn498, eNOS: Asn267), which is supported by less bulkier 3rd shell amino acids in human iNOS (Val/Phe) compared to eNOS (Leu/Ile) and nNOS (Leu/Phe). In the murine iNOS $\mathrm{Ox} \cdot 17$ structure, the rotation of Arg260 is tolerated by the presence of Thr277 and Ser256 in the vicinity resembling a 'Gln-open' conformation as in human iNOS. Taken together, we would expect distinct conformations of the imidazo[4,5-b]pyridine ring in eNOS and nNOS with disfavoured interactions, explaining the observed isoform selectivity. The crystal structures of human NOS isoforms in complex with $\mathbf{1 7}$ would be of great value to address this hypothesis. We have recently demonstrated, that 17 irreversibly inactivates murine iNOS by an NADPHand time-dependent mechanism leading to uncoupled electron transfer and heme loss. ${ }^{33}$ However, this time-dependent inhibition was not observed for nNOS. Structural differences in the binding site of $\mathbf{1 7}$ between the NOS isoforms might contribute in this inactivation mechanism.

Selected results of our subsequent SAR evaluation are summarized in Table 4 . In the series of $\mathbf{7 - s u b s t i t u t e d} \mathbf{1 7}$ derivatives, a significant drop in iNOS binding affinity was observed. The introduction of a 7-methoxy group resulted in a 10 -fold reduction of potency (22; iNOS: $\mathrm{pIC}_{50}=6.11$ ) as well as the 7-ethoxy-methoxy- (23; iNOS: $\mathrm{pIC}_{50}=6.29$ ) and the 7-phenethyloxy-derivative (24; iNOS: $\left.\mathrm{plC}_{50}=6.14\right)$ of 17 . This might be due to less favourable
Table 4

Inhibitory activities of further selected compounds against human NOS

Elry

interactions displayed by these 7-substituents in the corresponding part of the binding site as seen in our docking studies.

In contrast, the exemplified 6-derivatives of $\mathbf{1 7}$ having a $n$-butyl (25; iNOS: $\mathrm{plC}_{50}=7.26$ ) and phenyl substituent (26; iNOS: $\mathrm{pIC}_{50}=7.41$ ) both demonstrate a gain in iNOS affinity. The murine iNOS $_{0 x} \cdot 17$ structure indicates a hydrophobic contact area formed by Trp84 (human iNOS: Trp90), Met114 (Met120), Ser256 (Ala262), Arg260 (Arg266) within 8 Á distance to the 6-position of the imidazo[4,5-b]pyridine ring (Fig. 4). This hydrophobic region is probably addressed by the $n$-butyl and phenyl substituents of $\mathbf{2 5}$

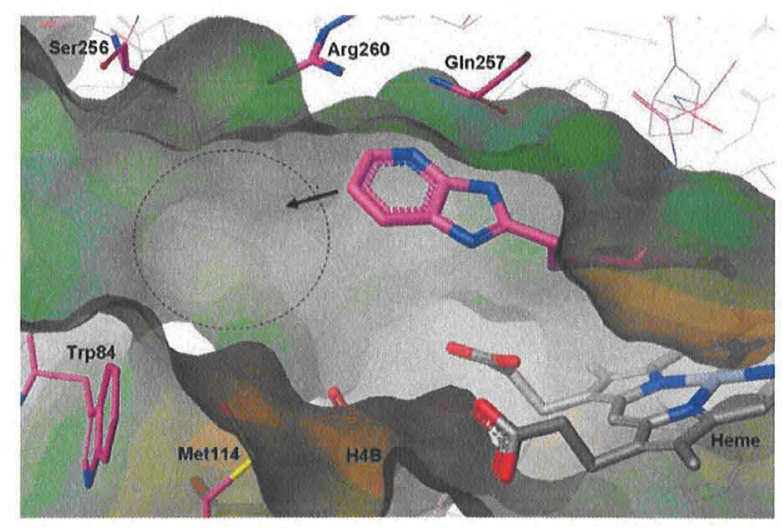

Figure 4. Connolly surface coloured by lipophilic potential (green: polar, brown: hydrophobic) calculated for the X-ray structure of murine iNOS (magenta) in complex with 17 indicates a hydrophobic contact area formed by Trp84. Met114, Ser256, Arg260. This area (dotted circle) is adressed by, for example, $n$-butyl and phenyl substituents in the 6-position of the imidazo[4,5-b]pyridine (marked by an arrow) leading to improved iNOS affinity. 
Table 5

Pharmacokinetic data and CYP P450 isoform profile ( $\mathrm{plC}_{50}$ )

\begin{tabular}{llll}
\hline Entry & \multicolumn{3}{l}{ Plharmacokinetic data (rat) } \\
\hline$C_{\max }[\mathrm{mg} / \mathrm{l}]$ & $F_{\text {abs }}[\%]$ & $\mathrm{CL}[\mathrm{I} / \mathrm{h} \mathrm{kg}]$ \\
\hline
\end{tabular}

and 26 leading to enhanced iNOS affinity and demonstrating a guideline for further structure-based optimization.

BYK 19102317 as representative of the discussed imidazo [4,5-b]pyridines displayed favorable pharmacokinetic parameters along with a clean CYP P450 isoform inhibition profile (Table 5) and drug-like physicochemical properties (data not shown). A comprehensive pharmacological assessment for $\mathbf{1 7}$ had been published elsewhere. $23,34,35$

In conclusion, we have demonstrated valuable structural insights for identifying and evaluating structure-activity relationships of potent and isoform selective iNOS inhibitors starting from initial HTS results. Binding mode of $\mathbf{1 7}$ guided us to rationalize our experimental SAR and to drive the design of inhibitors. iNOS inhibitors 17-26 represent selected structures capable of illustrating rationals and conclusions. Moreover, we described a straightforward synthetic access, favorable pharmacokinetic and CYP P450 data of the lead structure $\mathbf{1 7}$ as representative of the introduced iNOS inhibitor class.

\section{Acknowledgment}

We thank B. Bössenecker for determination of the $\mathrm{p} K_{\mathrm{a}}$-values.

\section{References and notes}

1. Alderton, W. K.; Cooper, C. E.; Knowles, G. Biochem. J. 2001, 357, 593.

2. Nakane, M.; Schmidt, H. H.; Pollock, J. S.; Forstermann, U.; Murad, F. FEBS Lett. 1993, $3.16,175$

3. Geller, D. A.; Lowenstein, C. J.; Shapiro, R. A.; Nussler, A. K.; Di Silvio, M.; Wang S. C.; Nakayama, D. K.; Simmons, R. L.; Snyder, S. H.; Billiar, T. R. Proc. Natl. Acad. Sci. U.S.A. 1993, 90, 3491

4. Marsden, P. A.; Schappert, K. T.; Chen, H. S.; Flowers, M.; Sundell, C. L.; Wilcox, J. N.; Lamas, S.; Michel, T. FEBS Lett. 1992, 307, 287.

5. Nichida, C. R.; Ortiz de Montellano, P. R. J. Biol. Chem. 2001, 276, 20116.

6. Hobbs, A. J.; Higgs, A.; Moncada, S. Annu. Rev. Pharmacol. Toxicol. 1999, 39, 191.

7. Salerno, L.; Sorrenti, V.; Di Giacomo, C.; Romeo, G.; Siracusa, M. A. Curr. Pharm. Des, 2002, 8, 177

8. Crane, B. R.; Arvai, A. S.; Gachhui, R.; Wu, C.; Ghosh, D. K.; Getzoff, E. D.; Stuehr, D. J.: Tainer, J. A. Science 1997, 278, 425

9. Hallinan, E. A.; Tsymbalov, S.; Dorn, C. R.; Pitzele, B. S.; Hansen, D. W. J. Med. Chem. 2002, 45, 1686.

10. Hansel, T. T.; Kharitonov, S. A.; Donnelly, L. E.; Erin, E. M.; Currie, M. G.; Moore, W. M.; Manning, P. T.; Recker, D. P. Barnes, P. J. FASEB J. 2003, 17(10), 1298.

11. Naka, M.; Nanbu, T.; Kobayashi, K.; Kamanaka, Y.; Komeno, M.; Yanase, R. Fukutomi, T.; Fujimura, S.; Seo, H. G.; Fujiwara, N.; Ohuchida, S.; Suzuki, K.; Kondo, K.; Taniguchi, N. Biochem. Biophys. Res. Commun. 2000, 270(2), 663.
12. Fischmann, T. O.; Hruza, A.; Xiao, D. N.; Fossetta, J. D.; Lunn, C. A.; Dolphin, E.; Prongay, A. J.; Reichert, P.; Lundell, D. J.; Narula, S. K.; Weber, P. C. Nat. Struct. Biol. 1999, 6, 233.

13. Li, H.; Shimizu, H.; Flinspach, M.; Jamal, J.; Yang, W.; Xian, M.; Cai, T.; Wen, E. Z.; Jia, Q.; Wang, P. G.; Poulos, T. L. Biochemistry 2002, 41, 13868.

14. Babu, B. R.; Griffith, O. W. Curr. Opin. Chem. Biol. 1998, 2, 491.

15. (a) Young, R. J.; Beams, R. M.; Carter, K.; Clark, H. A.; Coe, D. M.; Chambers, C. L. Davies, P. I.; Dawson, J.; Drysdale, M. J.; Franzman, K. W. Bioorg. Med. Chem. Lett. 2000, 10, 597; (b) Alderton, W. K.; Angell, A. D.; Craig, C.; Dawson, J.; Garvey, E. Moncada, S.; Monkhouse, J.; Rees, D.; Russel, R. J.; Schwartz, S. Br. J. Pharmacol. $2005,145,301$

16. Fedorow, R.; Hartmann, E.; Ghosh, D. K.; Schlichting, I. J. Biol. Chem. 2003, 278 45818.

17. Tinker, A. C.; Beaton, H. G.; Boughton-Smith, N.; Cook, T. R.; Cooper, S. L.; Fraser-Rae, L.; Hallam, K.; Hamley, P.; McInally, T.; Nicholls, D. J.; Pimm, A. D. Wallace, A. V. J. Med. Chem. 2003, 46, 913.

18. Hagmann, W. K.; Caldwell, C. G.; Chen, P.; Durette, P. L.; Esser, C. K.; Lanza, T. J.; Kopka, I. E.; Guthikonda, R.; Shah, S. K.; MacCoss, M.; Chabin, R. M.; Fletcher, D. Bioorg. Med. Chem. Lett. 2000, 10, 1975.

19. Connolly, S.; Aberg, A.; Arvai, A.; Beaton, H. G.; Cheshire, D. R.; Cook, A. R. Cooper, S.; Cox, D.; Hamley, P.; Mallinder, P.; Millichip, I.; Nicholls, D. J.; Rosenfeld, R. J.; St-Gallay, S. A.; Tainer, J.; Tinker, A. C.; Wallace, A. V. J. Med Chem. 2004, 47, 3320

20. Bonnefous, C.; Payne, J. E.; Roppe, J.; Zhuang, H.; Chen, X.; Symons, K. T.; Nguyen, P. M.; Sablad, M.; Rozenkrants, N.; Zhang, Y.; Wang, L.; Severance, D.: Walsh, J. P.; Yazdani, N.; Shiau, A. K.; Noble, S. A.; Rix, P.; Rao, T. S.; Hassig, C. A. Smith, N. D. J. Med. Chem. 2009, 52, 3047.

21. Zhou, D.; Lee, H.; Rothfuss, J. M.; Chen, D. L.; Ponde, D. E.; Welch, M. J.; Mach, R. H. J. Med. Chem. 2009, 52, 2443.

22. Martin, N. I.; Beeson, W. T.; Woodward, J. J.; Marletta, M. A. J. Med. Chem. 2008 51,924 .

23. Strub, A.; Ulrich, W.-R.; Hesslinger, C.; Eltze, M.; Fuchß, T.; Strassner, J.; Strand S.; Lehner, M. D.; Boer, R. Mol. Pharmacol. 2006, 69, 328.

24. Boer, R.; Marx, D.; Eltze, M.; Klein, T.; Nave, R.; Graedler, U.; Fuchss, T.; Barsig, J.: Ulrich, W-R. PCT Int. Appl. 2003, WO 2003080607 A1.

25. Ashimori, A.; Ono, T.; Uchida, T.; Ohtaki, Y.; Fukaya, C.; Watanabe, M.; Yokoyama, K. Chem. Pharm. Bull. 1990, 38, 2446.

26. Details of the experimental procedures can be found in the Supplementary data. RCSB Protein Data Bank; entry code 3NW2.

27. Rosenfeld, R. J.; Garcin, E. D.: Panda, K.; Andersson, G.; Aberg, A.; Wallace, A. V.; Morris, G. M.; Olson, A. J.; Stuehr, D. J.; Tainer, J. A.; Getzoff, E. D. Biochemistry $2002,41,13915$

28. Li, H.; Raman, C. S.; Glaser, C. B; Blasko, E.; Young, T. A; Parkinson, J. F. Whitlow, M.; Poulos, T, L. J. Biol. Chem. 1999, 274, 21276.

29. Cocco, L.; Roth, B.; Temple, C., Jr.; Montgomery, J. A.; London, R. E.; Blakley, R. L. Arch. Biochem. Biophys. 1983, 226, 567.

30. Czodrowski, P.; Dramburg, I.; Sotriffer, C. A.; Klebe, G. Proteins Struct. Funct. Bioinf. 2006, 65, 424.

31. Babu, B. R.; Frey, C.; Griffith, O. W. J. Biol. Chem. 1999, 274, 25218.

32. Garcin, E. D.; Arvai, A. S.; Rosenfeld, R. J.; Kroeger, M. D.; Crane, B. R.; Andersson, G.; Andrews, G.; Hamley, P. J.: Mallinder, P. R.; Nicholls, D. J.; StGallay, S. A.; Tinker, A. C.; Gensmantel, N. P.; Mete, A.; Cheshire, D. R.; Connolly, S.; Stuehr, D. J.; Aberg, A.; Wallace, A. V.; Tainer, J. A.; Getzoff, E. D. Nat. Chem. Biol. 2008, 4(11), 700

33. Tiso, M.; Strub, A.; Hesslinger, C.; Kenney, C. T.; Boer, R.; Stuehr, D. J. Mol. Pharmacol. 2008, 73(4), 1244.

34. Lehner, M. D.; Marx, D.; Boer, R.; Strub, A.; Hesslinger, C.; Eltze, M.; Ulrich, W. R.; Schwoebel, F.; Schermuly, R. T.; Barsig. J. J. Pharmacol. Exp. Ther. 2006, $317(1), 181$.

35. Hesslinger, C.; Strub, A; Boer, R.; Lehner, M. D.; Braun, C. Biochem. Soc. Trans. 2009, 37, 886. 